\title{
ESPÉCIES EMPREGADAS NA ARBORIZAÇÃO URBANA DO BAIRRO SANTIAGO, JI-PARANÁ/RO
}

\author{
Antonio dos Santos Junior ${ }^{1}$, Leila Maria Costa ${ }^{2} 3$
}

\section{RESUMO}

Os objetivos deste estudo foram descrever a composição e a estrutura da arborização pública e calcular a densidade metro linear de árvores no Bairro Santiago em Ji-Paraná/RO, uma cidade no Bioma Amazônico brasileiro. Adotamos a abordagem dada pela Densidade Metro Linear - DML - registrando para todas as árvores e palmeiras, presentes no trecho de passeio público estudado, o diâmetro na altura do peito (DAP) e os conflitos com a rede elétrica e de telecomunicações. A suficiência amostral foi verificada com o uso de uma curva de rarefação com a função Chao 1. Além disso, calculamos a freqüência relativa e a abundância relativa das espécies amostradas. A arborização urbana do Bairro Santiago em Ji-Paraná é caracterizada por uma pequena riqueza de espécies, que é compensada pela grande densidade de árvores plantadas (DML). A vegetação do Bairro é composta predominantemente por quatro espécies: F. benjamina, C. peltophoroides, S. malaccense e $L$. tomentosa. As distribuições das árvores de $F$. benjamina e $C$. peltophoroides em função do DAP sugerem a ocorrência de fases de modismo durante o plantio das árvores. O registro de conflitos com a infra-estrutura aérea, bem como uso massivo de espécies exóticas repetem o padrão observado em outras localidades do país.

Palavras-chave: Inventário de espécies; Espécies exóticas; Floresta Amazônica brasileira.

\section{TREES SPECIES USED IN URBAN FORESTRY OF SANTIAGO NEIGHBORHOOD, JI-PARANÁ/RO}

\section{ABSTRACT}

The objectives of this study were to describe the composition and structure of public forestry and calculate the density of trees linear meter in the Santiago neighborhood, in Ji-Paraná/RO, a town in the Brazilian Amazon Biome. We adopted the approach given by the Linear Metro Density - LMD - registering the diameter at breast height (DBH) and the conflicts with the electric and telecommunications networks of all tress and palm trees present in the stretch of the public promenade studied. Sample sufficiency was verified by the use of a rarefaction curve with function Chao 1 . Besides, we calculated the relative frequency and the relative abundance of sampled species. Urban forestry of Santiago Neighborhood in Ji-Paraná is characterized by a small richness of species, which is compensated by the high density of planted trees (LMD). The vegetation of the neighborhood is composed predominantly by four species: F. benjamina, C. peltophoroides, S. malaccense and L. tomentosa. The distributions of trees of the $F$. benjamina and $C$. peltophoroides species in function of DBH, suggest the occurrence of fashion trends during the planting of the trees. The occurrence of conflicts with the air infrastructure, as well as the massive use of exotic species repeat the pattern observed in other places in the country.

Key words: Inventory of species;Exotic species; Brazilian Amazon Forest.

\footnotetext{
${ }^{1}$ Biólogo, Doutor em Ecologia, Instituto Federal de Educação, Ciência e Tecnologia de Rondônia - IFRO, Av. Jorge Teixeira, 3146, Setor Industrial, Porto Velho, RO, CEP 76.821-002, antonio.junior@ifro.edu.br (autor para correspondência)

${ }^{2}$ Acadêmica de Ciências Biológicas, Centro Universitário Luterano de Ji-Paraná/ULBRA, Av. Engº. Manfredo Barata A. da Fonseca, 762, Jardim Aurélio Bernardi, CEP 76.907-438, Ji-Paraná, Rondônia, leilabio09@gmail.com

${ }^{3}$ recebido em 19.05.2012 e aceito para publicação em 15.03.2014
} 
A arborização urbana ou arborização pública pode ser definida de diferentes formas, entre elas: como os elementos vegetais arbóreos que estão plantados nas cidades, ou pela plantação de árvores de porte arbóreo em praças, parques e calçadas das vias públicas (LIMA et al., 1994; SANTOS et al., 2008). A despeito das variadas definições, a arborização urbana é hoje uma das mais relevantes atividades da gestão de cidades, devendo fazer parte dos planos, projetos e programas urbanísticos (SANTOS et al., 2008).

As árvores nas cidades desempenham algumas funções consideradas importantes para a população humana residente. A vegetação filtra os ruídos, amenizando a poluição sonora, produz sombreamento, resfriando a temperatura da superfície urbana e, ainda, melhora a qualidade do ar pelo aumento do teor de oxigênio e de umidade. A arborização urbana, também, diminui o efeito agressivo das construções que dominam a paisagem das cidades, bem como guarnece, identifica e emoldura as ruas e avenidas. Por último, embora difícil de quantificar, há o aspecto psicológico, que envolve a satisfação que o indivíduo sente ao contato com a vegetação e com o ambiente que ela cria (GRAZIANO, 1994; MASCARO et al., 2004).

Ademais, a arborização urbana em logradouros, praças e parques deve receber destaque em termos conservacionistas, pois representa redutos para a fauna e flora local (PEREIRA et al., 2005), em muitos casos abrigam espécies ameaçadas de extinção, como Araucaria angustifolia (BRASIL, 2008; OLIVEIRA et al., 2009; ALBERTIN et al., 2011). Tal função, de importância exclusivamente ambiental, reforça o caráter de bem tutelado e difuso (SILVA, 1997).
O plantio de árvores nas cidades requer cuidados especiais, principalmente quando são consideradas as décadas necessárias para a obtenção de um conjunto de árvores que cumpram as funções acima indicadas. A escolha de uma espécie inadequada para dado trecho da malha urbana pode não fornecer os benefícios esperados, além de interferir na infra-estrutura de distribuição de energia elétrica, iluminação pública e de telecomunicações, além de criar obstáculos para a circulação de pedestres e problemas como o entupimento de calhas e danos às redes água e de esgoto (MONTEIRO JUNIOR, 2000; MASCARO et al., 2004).

A escolha de uma espécie deve atender às condições específicas da área, cabendo à prefeitura planejar e orientar a comunidade. Por exemplo, devem-se evitar espécies com espinhos no tronco e que apresentem princípio ativo tóxico (alérgico) e dar preferência às espécies nativas da região, enriquecendo assim a flora local (PORTO ALEGRE, 2002; PEREIRA et al., 2005). Para isso, há de se observar criteriosamente a escolha da espécie vegetal, às limitações do local de implantação, o processo de formação da muda e cuidados durante o plantio e manutenção. Além desses cuidados, são necessárias políticas que apóiem e incentivem a implantação e manutenção das árvores nas cidades. A participação e o envolvimento da população são fundamentais para que as áreas verdes e a arborização urbana possam trazer benefícios à cidade e a seus moradores (PEREIRA et al., 2005; OLIVEIRA et al., 2009).

Os objetivos deste estudo foram descrever a composição e a estrutura da arborização pública e calcular a densidade metro linear de árvores no Bairro Santiago em Ji-Paraná/RO.

ESPÉCIES EMPREGADAS NA ARBORIZAÇÃO URBANA... 
O município de Ji-Paraná possui 107.679 habitantes e está localizado na região central (S 10 53’ 07” W 61 57' 06”) do estado de Rondônia, distando $327 \mathrm{~km}$ da capital Porto Velho (IBGE, 2010). Localizado na Amazônia Ocidental, o Estado de Rondônia não sofre grandes influências do mar ou da altitude. O clima predominante é do tipo Tropical Chuvoso, com precipitação média anual de $2.250 \mathrm{~mm}$. A média anual climatológica da temperatura do ar é de $23^{\circ} \mathrm{C}$. Há uma fase estiagem bem definida entre os meses de junho e setembro, quando ocorre na região um moderado déficit hídrico, com índices pluviométricos inferiores a 50 mm/mês. A média climatológica da precipitação pluvial para os meses de junho, julho e agosto é inferior a 20 mm/mês (SEDAM, 2010).

A área de estudo localiza-se no Bairro Santiago, noroeste da cidade de Ji-Paraná, saída sentido Porto Velho. O bairro é residencial e comercial, contendo duas indústrias madeireiras, localizada às margens da rodovia BR 364. Algumas ruas são pavimentadas e outras não. As casas são abastecidas por: água, luz, telefone e iluminação pública.

A arborização urbana, constituída de árvores distribuída linearmente ao longo de logradouros públicos, mostra uma estrutura consideravelmente distinta de florestas. Neste contexto, as técnicas usuais de amostragem da vegetação, como coleta de dados com parcelas de tamanho fixo ou de tamanho variável (DURIGAN, 2003), não se prestam ao estudo deste componente do ecossistema urbano. Para superar tal dificuldade, adotamos a abordagem dada pela Densidade Metro Linear - DML (CRISPIN, 2000; ROCHA et al., 2004; SOUZA e CINTRA, 2007). Para tanto, a coleta de dados empregou 55 linhas de $60 \mathrm{~m}$ dispostas assistematicamente ao longo do passeio público, totalizando $3.300 \mathrm{~m}$ lineares de amostragem no Bairro Santiago em Ji-Paraná/RO. A densidade metro linear da arborização urbana foi calculada dividindo o número total de indivíduos registrados no intervalo de amostragem pela extensão total de passeio público amostrado. Todas as árvores e palmeiras inseridas no intervalo de cada linha foram amostradas e identificadas quanto à espécie e origem utilizando guias de identificação (LORENZI, 2002ab; 2003)

No mês de agosto de 2010, anotou-se para todas as árvores e palmeiras amostradas o diâmetro a altura do peito (DAP, medido a 1,3 m acima do solo), bem como os conflitos com a infra-estrutura de rede elétrica e rede de telecomunicações (LIMA, 1993; SOUZA e CINTRA, 2007).

A suficiência amostral foi verificada com o uso de uma curva de rarefação com a função Chao 1, na qual a riqueza estimada é igual à riqueza observada, somada ao quadrado do número de espécies representada por apenas um indivíduo nas amostras dividido pelo dobro do número de espécies com apenas dois indivíduos (SANTOS, 2003). A curva de rarefação foi calculada empregando o programa EstimateS®, versão 7.5.2 Windows (COLWELL, 2005).

A freqüência relativa das espécies foi calculada dividindo o número de linhas em que a espécie foi amostrada pelo total de linhas de amostragem, multiplicado por 100. A abundância relativa das espécies foi calculada dividindo o número de indivíduos da espécie pelo total de árvores amostradas em todas as linhas, multiplicado por 100 (SOUZA e CINTRA, 2007). 
Na área estudada foram amostrados 421 indivíduos distribuídos em 27 espécies pertencentes a 16 famílias numa extensão total de 3.300 metros lineares de amostragem (Tabela 1 ). A riqueza de espécie encontrada no Bairro Santiago pode ser considerada pequena quando comparada aos valores de riqueza de espécies apresentados por outros estudos. Por exemplo: 41 espécies no Bairro Nova Brasília em Ji-paraná, RO (PINTO, 2009); 41 espécies no Bairro Taquara no Rio de Janeiro, RJ (SOUZA e CINTRA, 2007); 46 espécies no Bairro Rancho Novo e 59 espécies no Bairro Centro, ambos no Rio de Janeiro, RJ (ROCHA et al., 2004). Esta pequena riqueza de espécies não pode ser considerada erro ou mesmo insuficiência de amostragem, pois o teste de rarefação de espécies realizado sugere que para o esforço amostral executado esperava-se encontrar 31 espécies, indicando que algumas espécies raras ou pouco abundantes provavelmente não foram amostradas (Figura 1). No entanto, as espécies mais comuns e abundantes que dão o aspecto geral da arborização do bairro em estudo foram registradas.

A relação espécie-área (RODRIGUES e PRIMACK, 2006) é uma hipótese que pode ser indicada para explicar a menor quantidade de espécies registradas no Bairro Santiago, desde que a área do bairro em questão seja próxima da metade dos outros bairros utilizados para comparação e, também, que não exista nenhum outro efeito de seleção ou remoção de espécies. Contudo, não foram encontradas informações que relatem área dos bairros anteriormente citados. Além disso, em bairros comerciais, os proprietários sentem a necessidade de destacar a fachada das lojas ou comércios e, então, agem reduzindo o número de árvores e de espécies. Para resolver esta questão, sugere-se a execução de um estudo que enfoque a relação espécie-área em arborização pública.

A densidade metro linear (DML) encontrada no Bairro Santiago foi de 0,12 árvores por metro linear, ou 1,2 árvore/palmeira a cada 10 metros de passeio público. Este valor é muito maior ao registrado em outros trabalhos. Por exemplo, a DML do Bairro Rancho Novo foi de 0,035 árvores por metro linear e do Bairro Centro foi de 0,026 árvores por metro linear, ambos em Nova Iguaçu, RJ (ROCHA et al., 2004). A DML Bairro Paulo Frontim foi de 0,05 árvores por metro linear e a do Bairro Vila Santa Cecília foi de 0,055 árvores por metro linear, ambos em Volta Redonda, RJ (CRISPIN, 2000). Enfim, a DML Bairro Taquara foi de 0,05 árvores por metro linear, na cidade de Rio de Janeiro, RJ (SOUZA e CINTRA, 2007). Portanto, apesar do Bairro Santiago apresentar uma menor diversidade de espécies, a densidade de árvores do Bairro é maior do que o usualmente encontrado em outras localidades do Brasil. Tal constatação, segundo relatos coletados, decorre do plantio de árvores realizado pelos próprios moradores, que enxergam o passeio público como uma extensão de seus jardins.

As cinco espécies mais abundantes representaram $70 \%$ do total de indivíduos registrados no Bairro Santiago. As demais espécies, em sua maioria, foram representadas por um número inferior a cinco árvores. A espécie Ficus benjamina (Figueirinha) representou $40 \%$ de todas as árvores que compõem a arborização urbana do Bairro Santiago (Tabela 1). A dominância de uma espécie na arborização urbana não é um fenômeno local. Há relatos similares para outras cidades no Brasil, por exemplo, em Piracicaba, Caesalpinia peltophoroides (Sibipiruna) representou 52\% das ESPÉCIES EMPREGADAS NA ARBORIZAÇÃO URBANA... 
árvores da cidade (LIMA, 1993) e, em Manaus, Licania tomentosa (Oiti) representa 29\% da arborização (COSTA e HIGUSHI, 1999). Essa dominância, entretanto, não desqualifica a arborização urbana, na medida em que são reconhecidas suas funções ambientais como sombreamento da superfície e evapotranspiração (MASCARO et al., 2004). Porém, é recomendado pela literatura que nenhuma espécie deve ultrapassar o limite de $10-15 \%$ do total de árvores da vegetação urbana, prevenindo a dominância de apenas uma espécie ou grupo de espécies e a propagação das pragas nas áreas urbanas (GREY e DENEKE, 1978 apud MILANO e DALCIN, 2000). As espécies com os maiores valores de freqüência relativa encontradas no Bairro Santiago foram $F$. benjamina (69,09\%), C. peltophoroides (38,18\%),
Syzygium malaccense (jambo) (30,90\%) e $L$. tomentosa (25,45\%) (Tabela 1). A freqüência relativa pode ser entendida como uma indicação da distribuição espacial. Neste sentido, espécies com os maiores valores de freqüência relativa estão distribuídas em uma área maior, isto é, a espécie é encontrada em várias porções do bairro.

Portanto, sob a perspectiva dos resultados para abundância e freqüência relativa das espécies empregadas na arborização urbana do Bairro Santiago, fica evidente que o aspecto visual padrão, ou fisionomia, da vegetação do bairro investigado é dado por apenas quatro espécies: $F$. benjamina, $C$. peltophoroides, S. malaccense e L. tomentosa.

Figura 1. Curva de rarefação (em preto) e curva de acumulação (em cinza) de espécies registradas na arborização urbana do Bairro Santiago em Ji-Paraná, RO, confeccionadas a partir de 1.000 aleatorizações na ordem das amostras (veja detalhes em Análise de Dados).

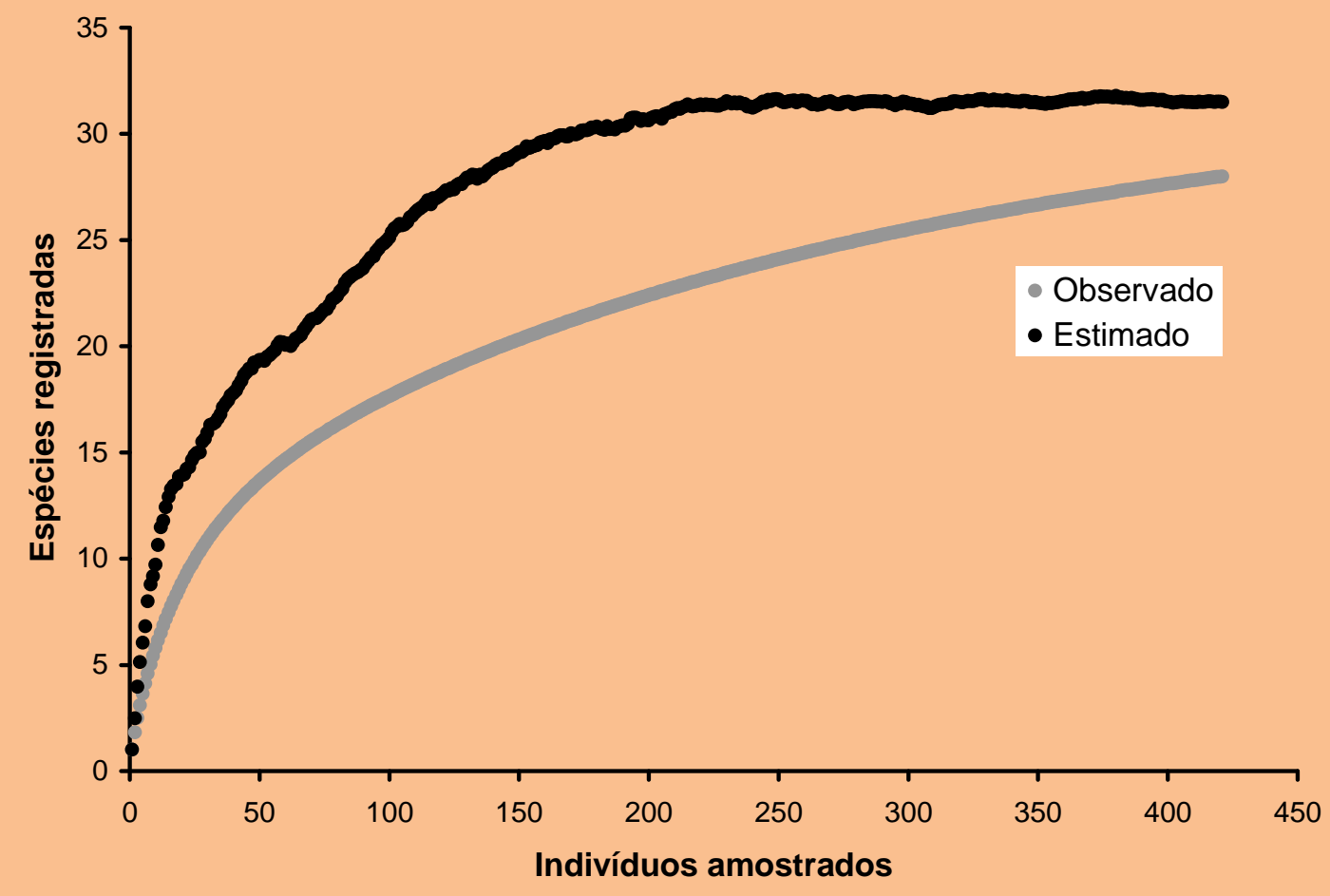


O DAP é usualmente empregado como uma medida indireta da idade das árvores. Os autores argumentam que árvores com maior DAP tendem a ser mais velhas (SCHAAF et al., 2006). Neste sentido, a população de F. benjamina é caracterizada pela maior representatividade das classes de DAP de 20 e $30 \mathrm{~cm}$, indicando um plantio recente. A população de $C$. peltophoroides é caracterizada pela maior representatividade das classes de DAP de 30, 40 e 50 cm de DAP, indicando um plantio mais antigo (Figura 2). A diferença aqui registrada, somada ao predomínio destas espécies na arborização do Bairro Santiago, pode ser considerada evidência de duas fases de modismos na arborização urbana, isto é, em determinada década ocorreu uma forte seleção de uma espécie para a composição da arborização do bairro, em detrimento das outras espécies disponíveis (MASCARO et al., 2004). A fase mais antiga marcada pelo plantio massivo de indivíduos de $C$. peltophoroides e, recentemente, o plantio massivo de árvores de F. benjamina.

Figura 2. Distribuição de árvores de Ficus banjamina (barras em branco) e de Caesalpinia peltophoroides (barras em preto) em função do Diâmetro na Altura do Peito (DAP) amostradas em inventário de espécies da arborização urbana do Bairro Santiago, Ji-Paraná, RO.

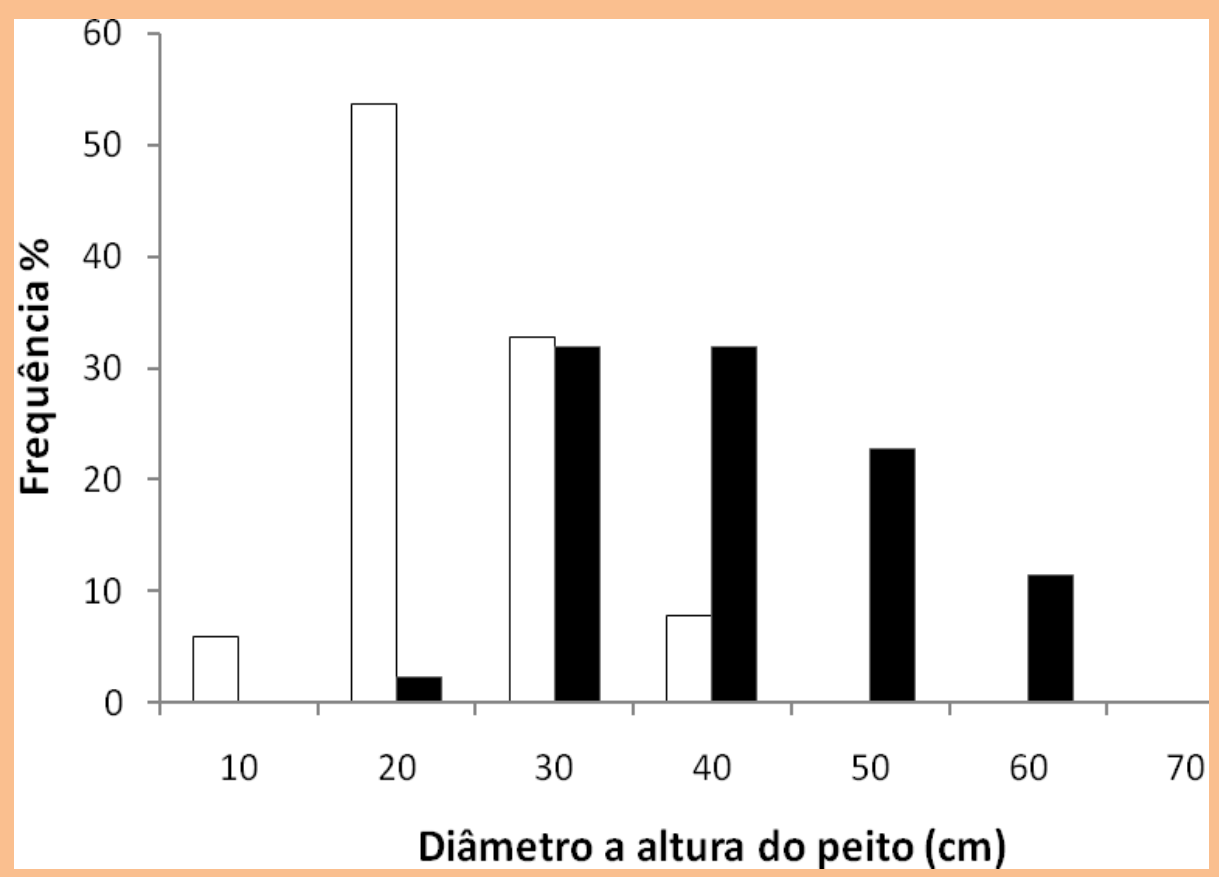


Das 421 árvores amostradas cerca de 30\% apresentaram conflitos com cabos aéreos de telecomunicações e de energia elétrica. Resultados semelhantes foram registrados nos municípios de Bandeirantes (PR) e Nova Iguaçu (RJ), nos quais 31\% e 35\% das árvores, respectivamente, exibiram conflitos com a infra-estrutura aérea (ROCHA et al., 2004; LIMA et al., 2007). As espécies $F$. benjamina e $C$. peltophoroides, dominantes na arborização do Bairro Santiago, foram as mais envolvidas nos conflitos registrados. O planejamento do plantio é a saída mais indicada para minimizar problemas entre a infraestrutura e a arborização urbana, partindo da escolha de espécies adequadas aliado à condução do crescimento (MILANO e DALCIN, 2000).

Apenas 6 das 27 espécies amostradas no Bairro Santiago em Ji-Paraná, RO, são nativas (Tabela 1). Foram consideradas espécies nativas apenas as que são de origem da Amazônia Brasileira. Espécies indicadas como ocorrentes no Brasil, mas naturais de outros Biomas, como Pampa ou Mata Atlântica, foram consideradas exóticas, pois não são naturais da Amazônia. Espécies indicadas como originárias de outros países, mesmo que subespontâneas, foram consideradas exóticas, pois, também, não são naturais da Amazônia. Para chegar nesta conclusão foram cruzadas as informações fornecidas pelos seguintes autores Lorenzi 2002, 2003; Forzza et al., 2010.

Constata-se que os responsáveis pelo plantio das árvores selecionaram espécies exóticas, tanto de outros países como de outros biomas brasileiros. Segundo o inventário relatado aqui, 78\% das espécies empregadas na arborização são exóticas. A predominância de espécies exóticas na arborização urbana é uma constante no Brasil, conforme relatos de outros estudos, variando de 99\% de exóticas em Pato Branco, PR (SILVA et al., 2007) a 53\% em Santa Maria, RS (TEIXEIRA et al., 2009). Estes resultados atestam o pouco prestígio das espécies arbóreas nativas com a população local, bem como com os gestores urbanos. Sugere-se um maior empenho dos órgãos públicos e da população para programar um plano de arborização que contemple espécies nativas. Isso demonstra, em parte, falta de interesse dos órgãos públicos em oferecer mudas da flora regional e em incentivar o plantio das mesmas pela população. 
Tabela 1. Famílias, espécies e origem de árvores registradas compondo a arborização pública do Bairro Santiago em Ji-Paraná, RO. (A\%: Abundância relativa; F\%: Frequência relativa). Foram consideradas nativas apenas as espécies que são de origem amazônica brasileira, segundo A= Forzza et al., 2010; B= Lorenzi, 2003; C= Lorenzi 2002.

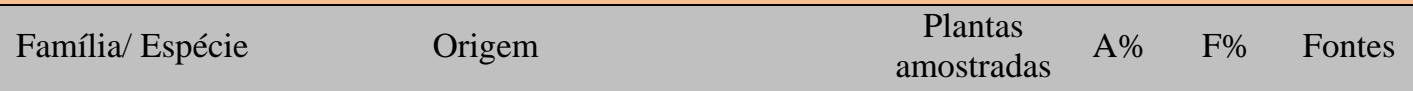

\section{ANACARDIACEAE}

Anacardium occidentale L. Nativa da Amazônia

Distribuição: nativa; não endêmica; Norte (RR, AP, PA, AM, TO, AC), Nordeste (MA, PI, CE, RN, PB, PE, BA, AL, SE), Centro-Oeste (MT, GO, DF), Sudeste (MG, ES, SP, RJ), Sul (PR, SC);

Amazônia, Caatinga, Cerrado, Mata Atlântica, Pampa,

Pantanal

Mangifera indica L.

Exótica na Amazônia 16 $3,80 \quad 16,36$

A, B

Distribuição: subespontânea; não endêmica; Norte (AP, PA, AM), Nordeste (MA, PE, $\mathrm{BA})$, Centro-Oeste (GO, MS), Sudeste (MG, ES, SP, RJ), Sul (PR, SC); Amazônia, Cerrado, Mata Atlântica

Natural da Índia

Schinus molle L.

Exótica na Amazônia 2 $0,47 \quad 3,63$

A, C

Distribuição: nativa; não endêmica; Sudeste (SP, RJ), Sul (PR, SC, RS); Mata Atlântica, Pampa

\section{ANNONACEAE}

Annona mucosa Jacq.

Nativa da Amazônia

1

A, C

Distribuição: nativa; não endêmica;

Norte (PA, AM, AC), Nordeste (BA),

Centro-Oeste (MT), Sudeste (MG,

RJ), Sul (RS); Amazônia, Cerrado, 
Mata Atlântica

Annona squamosa L. Exótica na Amazônia

$0,23 \quad 1,81 \quad$ B

Natural das Antilhas e Caribe

\section{ARECACEAE}

Areca triandra Roxb. Exótica na Amazônia

Natural da Índia e Malásia

Cocos nucifera L.

$$
\text { Exótica na Amazônia }
$$

3

$0,71 \quad 3,63 \quad$ A, C

Distribuição: subespontânea; não

endêmica; Nordeste (MA, PI, CE,

RN, PB, PE, BA, AL, SE), Sudeste

(ES, SP, RJ); Mata Atlântica

Mauritia flexuosa L.f. Nativa da Amazônia

2

$0,47 \quad 1,81 \quad$ A, C

Distribuição: nativa; não endêmica;

Norte (AM, TO, AC, RO),

Nordeste (MA, PI, CE, BA),

Sudeste (MG, SP); Amazônia,

Caatinga, Cerrado

$\begin{array}{ll}\begin{array}{l}\text { Roystonea oleracea } \\ \text { (Jacq.) O.F. Cook }\end{array} & \text { Exótica na Amazônia } \\ & \text { Natural das Antilhas, Venezuela, } \\ & \text { Colômbia }\end{array}$

$25 \quad 5,93 \quad 12,72 \quad$ B

BIGNONIACEAE

Spathodea campanulata

Exótica na Amazônia

3

$0,71 \quad 3,63$

B

P.Beauv.

Natural da África Central

\section{CAESALPINIACEAE}

Bauhinia variegata L. Exótica na Amazônia

0,95

3,63

B

Natural da Ásia

Caesalpinia

Exótica na Amazônia

44

$10,45 \quad 38,18$

C 
peltophoroides Benth

Cassia fistula L.
Distribuição: nativa; não endêmica;

Nordeste (BA), Centro-Oeste (MT,

MS), Sudeste (RJ, SP); Mata

Atlântica, Pantanal

Exótica na Amazônia

Natural da Ásia

\section{CHRYSOBALANACE}

AE

Licania tomentosa

(Benth.) Fritsch

Nativa da Amazônia

Distribuição: nativa; endêmica;

Nordeste (PI, CE, PB, PE, BA),

Centro-Oeste (MT, DF), Sudeste

(MG, SP, RJ); Amazônia

\section{COMBRETACEAE}

Terminalia catappa L. Exótica na Amazônia

Natural da Ásia

\section{CUPRESSACEAE}

Thuja occidentalis L.

\section{Exótica na Amazônia}

Natural do Canadá e EUA

\section{LYTHRACEAE}

Physocalymma

scaberrimum Pohl

Nativa da Amazônia

Distribuição: nativa; endêmica;

Norte (PA, TO, AC), Centro-Oeste

(MT, GO, DF); Amazônia, Cerrado
36

$8,55 \quad 25,45$

A, C
$0,23 \quad 1,81 \quad$ B 
MELIACEAE

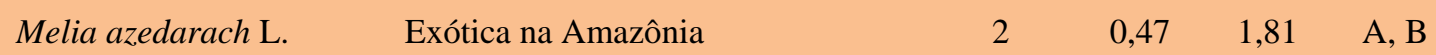

Distribuição: subespontânea; não endêmica; Norte (AC), Nordeste

(PI, CE, BA), Centro-Oeste (DF, MS), Sudeste (MG, ES, SP, RJ),

Sul (PR, SC); Amazônia, Caatinga,

Cerrado, Mata Atlântica.

Natural da Índia

\section{MORACEAE}

Ficus benjamina L.

Exótica na Amazônia

Natural da Ásia

Morus alba L.

Exótica na Amazônia

2

3,63

B

Natural da Ásia

\section{MYRTACEAE}

Syzygium cumini (L.) Exótica na Amazônia

1

$0,23 \quad 1,81$

A, B

Skeels

Distribuição: subespontânea; não endêmica; Norte (RR, AM),

Nordeste (PE, BA), Sudeste (MG,

ES, SP, RJ), Sul (PR, SC, RS);

Amazônia, Cerrado, Mata

Atlântica, Pantanal

Natural da Ásia

Syzygium malaccense

Exótica na Amazônia

28

$6,65 \quad 30,90$

B

(L.) Merr. \& Perry

Natural da Ásia

\section{RUTACEAE}

Citrus X limon (L.)

Osbeck

Exótica na Amazônia

1

0,23

1,81

A, B

Distribuição: subespontânea; não

endêmica; Centro-Oeste (GO, DF, 
MS), Sudeste (MG, SP), Sul (PR,

SC, RS); Cerrado, Mata Atlântica

Natural da Ásia

Murraya paniculata (L.) Exótica na Amazônia

Jack

Natural da Ásia

\section{VERBENACEAE}
Duranta erecta L.
Exótica na Amazônia
3
0,71
3,63
A, B
Distribuição: nativa; não endêmica;
Nordeste, Centro-Oeste; Mata
Atlântica, Cerrado
México, América Central e
América do Sul

\section{Indeterminada}

Indeterminada

1

0,23

1,81

16 famílias/27 espécies

421

100

árvores

$\%$

\section{CONCLUSÕES}

A arborização urbana do Bairro Santiago em JiParaná é caracterizada por uma pequena riqueza de espécies, que é compensada pela grande densidade de árvores plantadas (DML), tanto pelo poder público como pelos particulares. A vegetação do Bairro é composta predominantemente por quatro espécies: F. benjamina, C. peltophoroides, $S$. malaccense e L. tomentosa. As distribuições das árvores de $F$. benjamina e C. peltophoroides em função do DAP sugerem a ocorrência de fases de modismo durante o plantio das árvores. O registro de conflitos com a infra-estrutura aérea, bem como uso massivo de espécies exóticas repetem o padrão observado em outras localidades do país. 
Os autores são gratos à Laura Borges Nogueira pela revisão do abstract.

\section{REFERÊNCIAS BIBLIOGRÁFICAS}

ALBERTIN, R. M.; De ANGELIS, R.; NETO, G. A.; De Angelis, L. D. Diagnóstico quali-quantitativo da arborização viária de Nova Esperança, Paraná, Brasil. Revista da Sociedade Brasileira de Arborização Urbana, v. 6, n. 3, p. 128-148, 2011.

BRASIL. Instrução Normativa do Ministério do Meio Ambienta nº 6, de 23 de setembro 2008. Lex: Reconhecer as espécies da flora brasileira ameaçadas de extinção aquelas constantes do Anexo I a esta Instrução Normativa e Reconhece como espécies da flora brasileira com deficiência de dados aquelas constantes do Anexo II a esta Instrução Normativa. Brasília, DF, 55 pp. 2008.

COLWELL, R. K. 2005. EstimateS: Statistical estimation of species richness and shared species from samples. Version 7.5.2. for Windows. Persistent URL <purl.oclc.org/estimates>.

COSTA, L. A. C e HIGUCHI, N. Arborização de ruas de Manaus: avaliação qualitativa e quantitativa. Revista Árvore, v. 23, n.2, p. 223-232, 1999.

CRISPIN, A. A. Arborização urbana de Volta Redonda-RJ: levantamento nos Bairros Paulo de Frontin e Vila Santa Cecília. Soropédica, 2000. 180f. Dissertação (Mestrado em Ciências Ambientais e Florestais) Universidade Federal Rural do Rio de Janeiro, Seropédica, 2000.

DURIGAN, G. Métodos para análise de vegetação arbórea. In: CULLEN Jr, L.; VALLADARES-PADUA, C. e RUDRAN, R. (Orgs.). Métodos de estudos em biologia da conservação e manejo da vida silvestre. Curitiba: Editora da UFPR/Fundação O Boticário de Proteção à Natureza, 2003, p. 455-480.

RODRIGUES, E e PRIMACK, B. R. Biologia da Conservação. Londrina: Editora Planta, 2006.

FORZZA, R. C.; LEITMAN, P. M.; COSTA, A.; CARVALHO JR, A. A.; PEIXOTO, A. L.; WALTER, B. M. T.; BICUDO, C.; ZAPPI, D.; COSTA, D. P.; LLERAS, E.; MARTINELLI, G.; LIMA, H. C.; PRADO, J.; STEHMANN, J. R.; BAUMGRATZ, J. F. A.; PIRANI, J. R.; SYLVESTRE, L. S.; MAIA, L. C.; LOHMANN, L. G.; PAGANUCCI, L.; SILVEIRA, M.; NADRUZ, M.; MAMEDE, M. C. H.; BASTOS, M. N.; MORIM, M. P.; BARBOSA, M. R.; MENEZES, M.; HOPKINS, M.; SECCO, R.; CAVALCANTI, T. e SOUZA, V. C. Catálogo de plantas e fungos do Brasil. 1699pp. 2.v.il. Rio de Janeiro: Andrea Jakobsson Estúdio/Instituto de Pesquisas Jardim Botânico do Rio de Janeiro, 2010.

GRAZIANO, T. T. Viveiros Municipais. Jaboticabal: Departamento de Horticultura/FCAVJ/UNESP. 1994.

GREY, G. W. e DENEKE, F. J. Urban forestry. New York: John Wiley, 1978.

Demografia de Rondônia. In: INSTITUTO BRASILEIRO DE GEOGRAFIA E ESTATÍSTICA (IBGE). 2010. Disponível em: <http://www.ibge.gov.br/cidadesat/topwindow.htm?1>. Acesso em: 14 ago 2010.

LIMA. A. M. L. Analise da arborização viária na área central e em seu entorno. Piracicaba, SP. Piracicaba, 1993, 238f. Tese (Doutorado em Ciências Florestais) - Escola Superior de Agricultura Luiz de Queiroz, Universidade de São Paulo, Piracicaba, 1993.

LIMA. A. M. L. P.; CAVALEIRO, F.; NUCCI, J. C. e SOUSA, M. A. Problemas de utilização na conceituação de termos como espaços livres, áreas verdes e correlatos In: Congresso Brasileiro de Arborização Urbana, 2, São Luis. Anais... São Luís/Ma: UFMA, 1994.

LIMA, C. B.; BELLETTINA, N. M. T.; SILVA, A. S.; JANANI, J. K.; AMADOR, T. S.; VIEIRA, M. A. V. e CHEIRUBIM, A. P. LIMA. B.C. Descrição das árvores encontradas nas ruas de Bandeirantes/PR. Revista Brasileira de Biociências, vol. 5, supl. 1, p. 609-611, 2007.

LORENZI, H. Árvores Brasileiras: manual de identificação e cultivo de plantas arbóreas do Brasil. v.1. $4^{a}$ ed. Nova Odessa: Instituto Plantarum, 2002. 
LORENZI, H. Árvores Brasileiras: manual de identificação e cultivo de plantas arbóreas do Brasil. v.2. $4^{\text {a }}$ ed. Nova Odessa: Instituto Plantarum, 2002.

LORENZI, H. Árvores exóticas no Brasil. Nova Odessa: Instituto Plantarum. 2003.

MASCARO, L. A. E. R.; WEINGARTNER, G.; TRIVELLATO, F.; CUNHA, M. e SANTOS JÚNIOR, A. Arborização urbana em Campo Grande/MS: evolução e ambiência. Ensaios \& Ciência, v. 8, n. 3, p. 267-280, 2004.

MILANO, M. S. e DALCIN, E. Arborização de vias públicas. Rio de Janeiro: Light, 2000.

MONTEIRO JUNIOR, E. S. Sistema de produção de mudas de Tibouchina granulosa Cong. (quaresmeiraroxa) destinadas à arborização urbana. Lavras, 2000, 120f. Dissertação (Mestrado em Ciências Florestais) Universidade Federal de Lavras, Lavras, 2000.

OLIVEIRA, F. A. C.; SILVA, L. M.; HASSE, I.; CADORIN, D. A. e OLIVEIRA, K. A. Inventário da arborização do campus Pato Branco da Universidade Tecnológica Federal do Paraná - UTFPR. Revista da Sociedade Brasileira de Arborização Urbana, v. 4, n. 1, p. 93-106, 2009.

PEREIRA, G. A.; MONTEIRO, C. S.; CAMPELO, M. A. e MEDEIROS, C. O uso de espécies vegetais, como instrumento de biodiversidade da avifauna silvestre, na arborização pública: o caso do Recife. Atualidades ornitológicas, n. 125, p.10-24, 2005.

PINTO, M. C. Arborização urbana no município de Ji-Paraná/RO: o caso do Bairro Nova Brasília. JiParaná, 2009, 30f. Trabalho de Conclusão de Curso (Bacharelado em Ciências Biológicas) - Centro Universitário Luterano de Ji-Paraná, Ji-Paraná. 2009.

Secretaria Municipal do Meio Ambiente. Equipe do Plano Diretor de Arborização Urbana. Cartilha da arborização urbana. Porto Alegre-RS. 36p. 2002.

ROCHA, A. T.; SANTOS, P. S. e NETO, S. N. O. Arborização de vias publica em Nova Iguaçu, RJ: o caso dos Bairros Rancho Novo e Centro. Revista Árvore, v. 28, n. 4, p. 599-607, 2004.

SANTOS, A. R.; BERGALLO, H. G. e ROCHA, C. F. D. Paisagem urbana alienígena. Revista Ciência Hoje, vol. 41, n. 245, p. 68-70, 2008.

SANTOS, A. J. Estimativas de riqueza em espécie. In: CULLEN Jr, L.; VALLADARES-PADUA, C. e RUDRAN, R. (Orgs.). Métodos de estudos em biologia da conservação e manejo da vida silvestre. Curitiba: Editora da UFPR/Fundação O Boticário de Proteção à Natureza, 2003, p. 25-53.

SCHAAF, L. B.; FILHO, A. F.; FRANKLIN, G. e SANQUETTA C. B. Alteração na estrutura diamétrica de uma floresta ombrófita mista no período entre 1979 e 2000. Revista Árvore, v. 30, n. 2, p. 283-295, 2006.

Clima de Rondônia. In: SECRETARIA DE ESTADO DE DESENVOLVIMENTO AMBIENTAL (SEDAM). 2010. Disponível em: <http://www.sedam.ro.gov.br/web/guest/Meteorologia/Climatologia>. Acesso em: 01 set 2010.

SILVA, J. A. Direito Urbanístico Brasileiro. 2a ed. São Paulo: Malheiros Editores, 1997.

SILVA, L. M.; MOCCELLIN, R.; WEISHEIMER, D. I.; ZBORALSKI, A. R.; FONSECA, L. e RODIGHIERO, D. A. Inventário e sugestões para arborização em via pública de Pato Branco/PR. Revista da Sociedade Brasileira de Arborização Urbana, v. 2, n. 1, p. 101-108, 2007.

SOUZA, R.C. e CINTRA, D.P. Arborização viária e conflitos com equipamentos urbanos no Bairro Taquara, RJ. Revista Floresta e Ambiente, v. 14, n. 1, p. 45-51, 2007.

TEIXEIRA, I. F.; SANTOS, N. R. Z. e BALEST, S. S. Arborização de vias públicas: posição dos moradores de três loteamentos na cidade de Santa Maria (RS). Revista Ambiência, v. 5, n. 3, p. 457-474, 2009. 